Supplement of The Cryosphere, 13, 1513-1528, 2019

https://doi.org/10.5194/tc-13-1513-2019-supplement

(C) Author(s) 2019. This work is distributed under

the Creative Commons Attribution 4.0 License.

(c) (1)

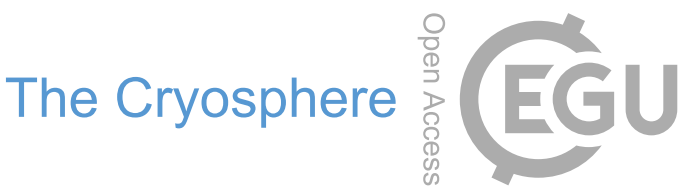

Supplement of

\title{
Rapid retreat of permafrost coastline observed with aerial drone photogrammetry
}

Andrew M. Cunliffe et al.

Correspondence to: Andrew M. Cunliffe (a.cunliffe@exeter.ac.uk)

The copyright of individual parts of the supplement might differ from the CC BY 4.0 License. 
Table S1. Processing parameters for photogrammetric reconstructions in Agisoft PhotoScan:

\begin{tabular}{|c|c|c|}
\hline Step & Parameter & Value \\
\hline Image quality assessment & Minimum quality score & $\geq 0.7$ \\
\hline \multirow[t]{6}{*}{ Image alignment } & Accuracy & Highest \\
\hline & Generic preselection & Yes \\
\hline & Reference preselection & Yes \\
\hline & Key point limit & 40,000 \\
\hline & Tie point limit & 0 \\
\hline & Adaptive camera model fitting & No \\
\hline Tie point filtering & Reprojection error threshold & 0.45 \\
\hline \multirow[t]{2}{*}{ Parameter optimisation } & Enabled parameters: & $\mathrm{F}, \mathrm{Cz}, \mathrm{Cy}, \mathrm{B} 1, \mathrm{~B} 2, \mathrm{~K} 1, \mathrm{~K} 2, \mathrm{~K} 3, \mathrm{P} 1, \mathrm{P} 2$ \\
\hline & Fit rolling shutter & No \\
\hline Dense cloud & Quality & High \\
\hline (Multi-view stereopsis) & Depth filtering & Mild \\
\hline \multirow[t]{4}{*}{ Orthomosaic } & Mapping mode & Orthophoto \\
\hline & Blending mode & Mosaic \\
\hline & Enable colour correction & Yes \\
\hline & Enable hole filling & Yes \\
\hline \multirow{5}{*}{$\begin{array}{l}\text { Digital Surface Model } \\
\text { (DSM) }\end{array}$} & Surface type & Height field \\
\hline & Source data & Dense cloud \\
\hline & Interpolation & Enabled \\
\hline & Quality & High \\
\hline & Depth filtering & Mild \\
\hline
\end{tabular}




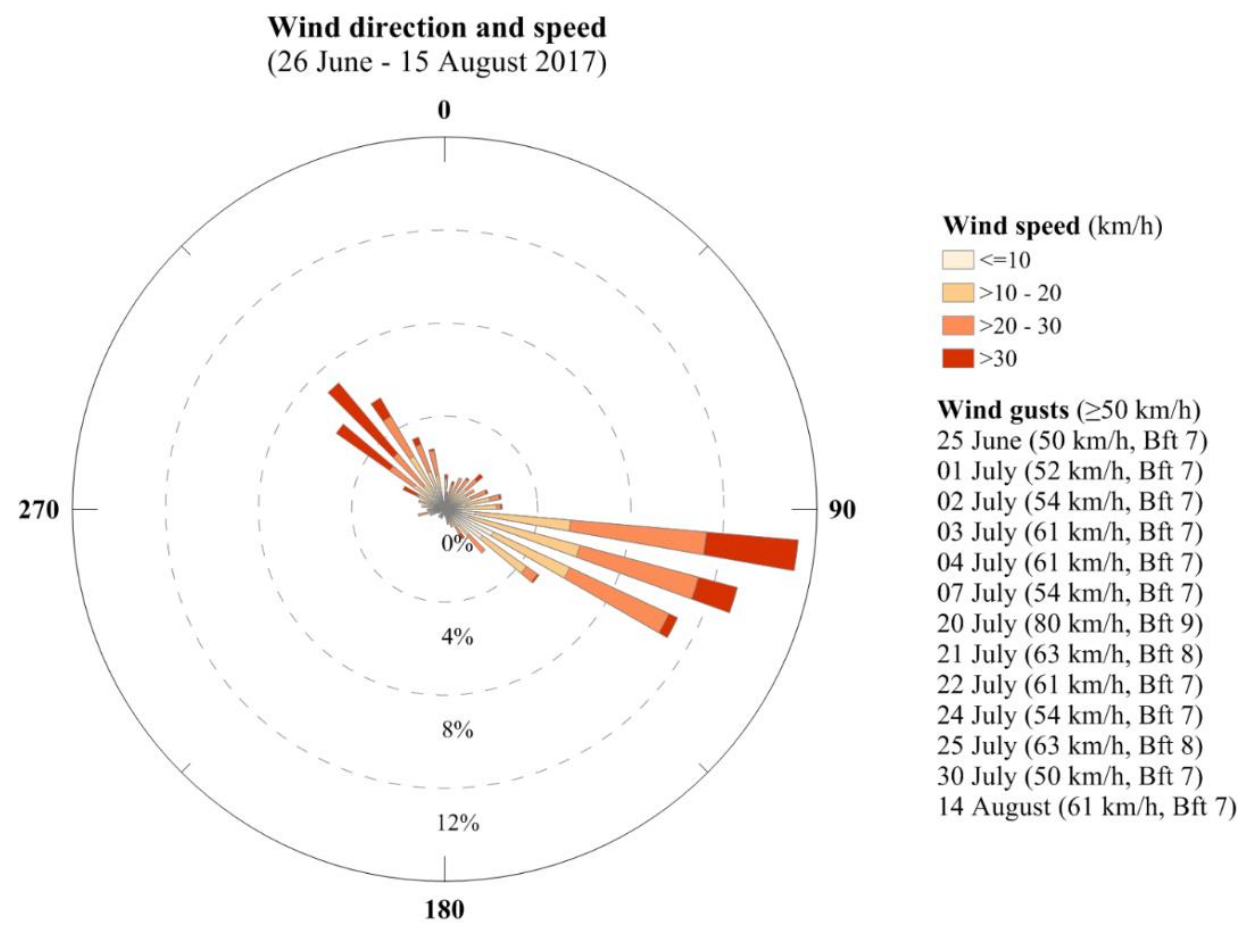

Figure S1. Wind direction, frequency and speed observed on Kuvluraq - Simpson Point, Qikiqtaruk Herschel Island from 2017-06-16 to 2017-08-15. Three strong easterly wind events (>30 km/h wind speed) were observed during the observation period; Data source: Environment Canada 2017.

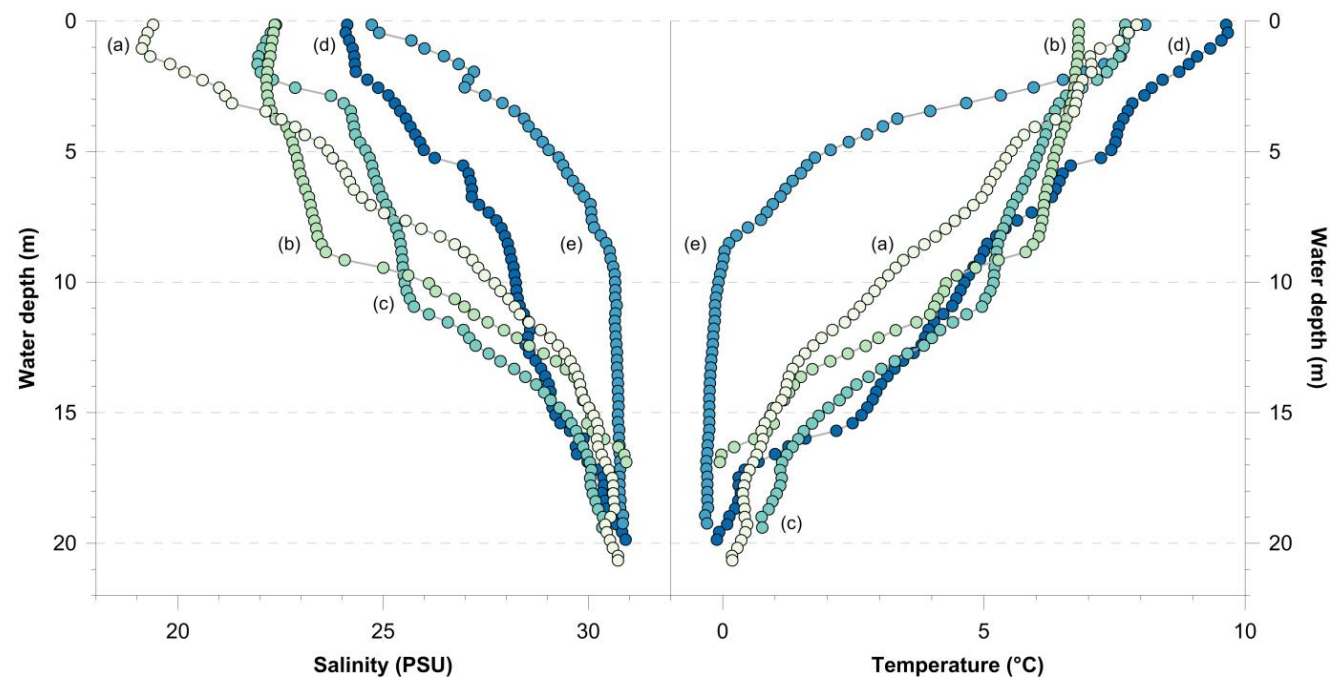

Figure S2. Seawater temperatures and salinity measured in close proximity to the land within $2 \mathrm{~km}$ of Kuvluraq - Simpson Point, made between 2017-07-21 and 2017-08-02; (a) 2017-07-21, (b) 2017-07-23, (c) 2017-07-25, (d) 2017-07-28, and (e) 2017-08-02. 


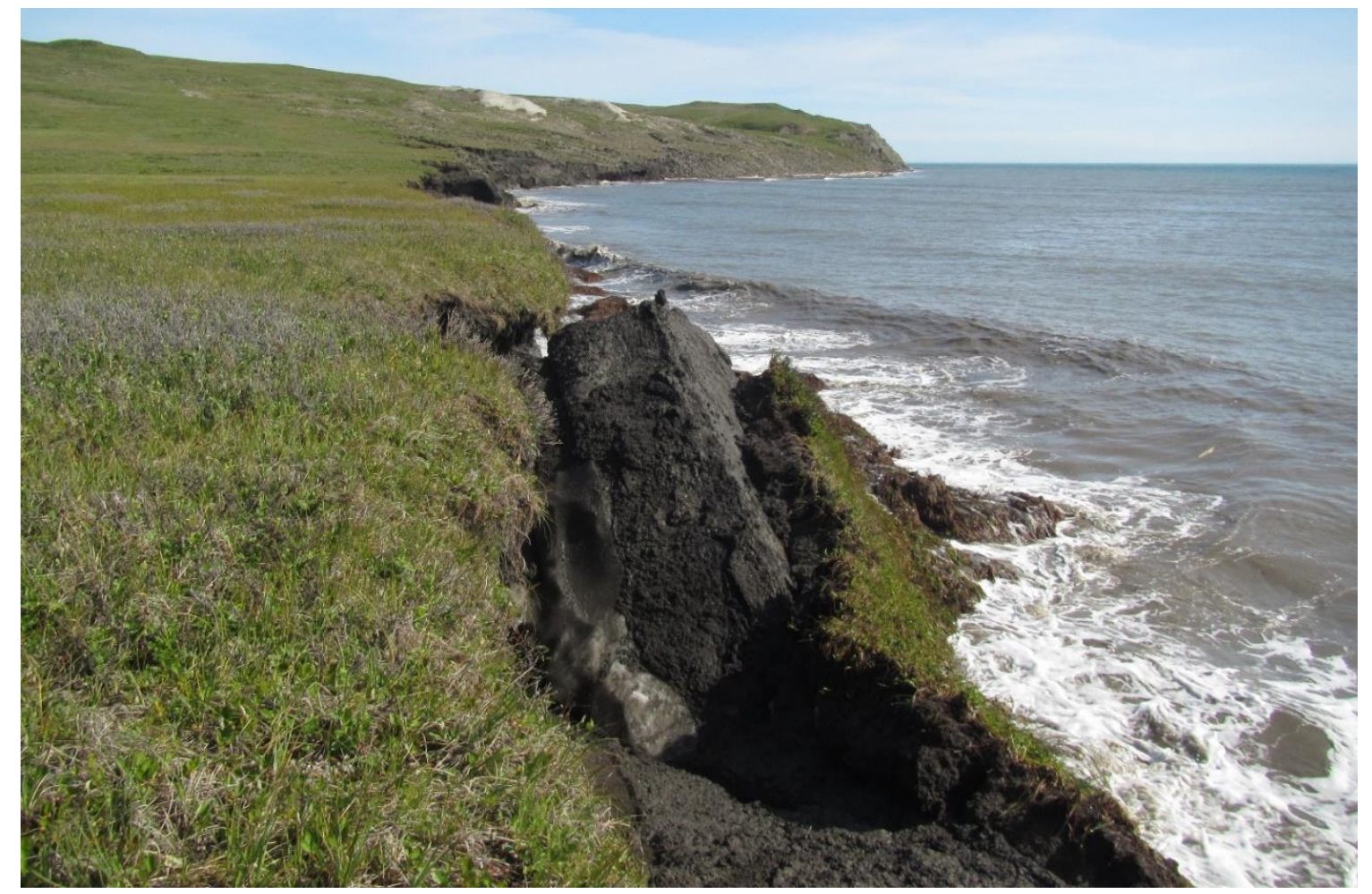

Figure S3. Example of cliff erosion via block failure due to undercutting. The vegetated active layer (i.e.

seasonally thawed part of the soil) has subsequently detached from the collapsed block.

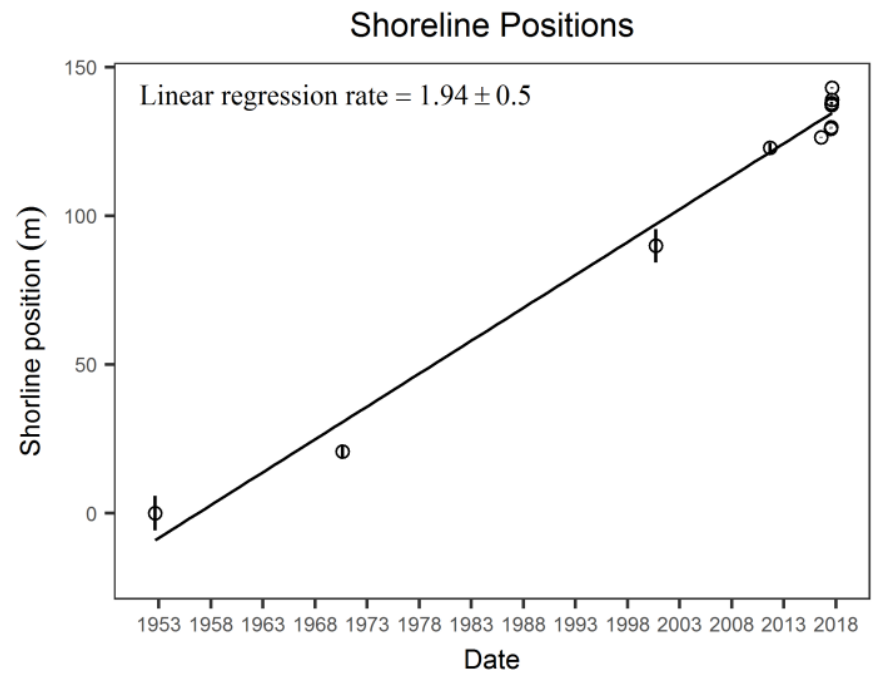

Figure S4. Change in mean shoreline position for all time points, $y$-axis errors represent total shoreline uncertainty (Table 1). The solid line is a linear model, fitted by least squares, and has a slope of $1.94 \pm 0.5\left(\mathrm{~m} \mathrm{yr}^{-1} ; \pm \mathrm{SE}\right)$. 


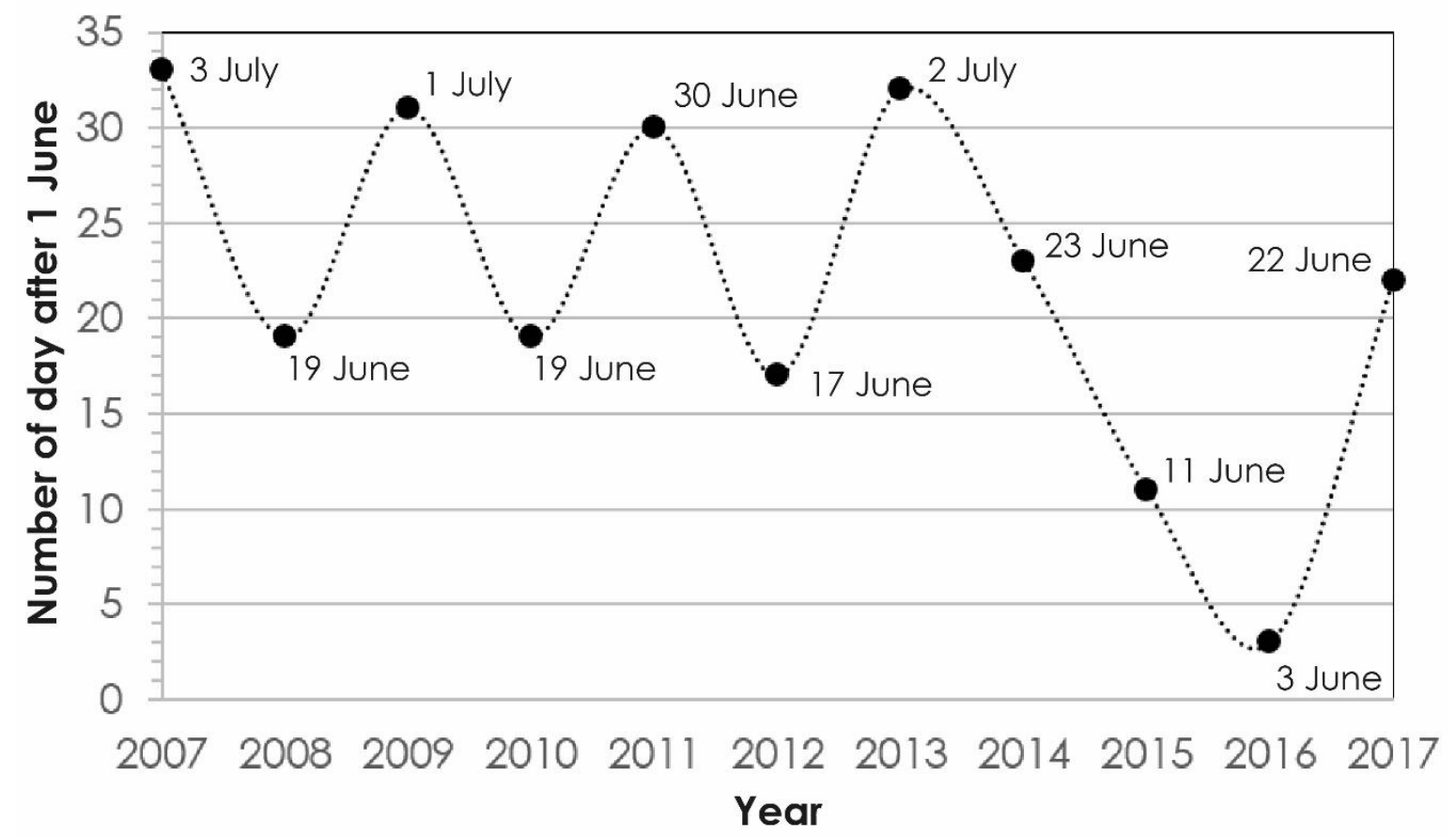

Figure S5. Start of the open water season, extracted from MODIS observations (Nasa WorldView, https://worldview.earthdata.nasa.gov/). The two years preceding 2017 experienced early than typical break up, but 2017 was in line with the decadal average.

Video S1. Created from hourly time-lapse images, looking west by southwest towards the Pauline Cove settlement from $69.570553^{\circ} \mathrm{N},-138.880706^{\circ} \mathrm{E}$, between $2017-07-29$ and $2017-08-03$. Available online at https://doi.org/10.5446/40250.

\section{References:}

ESRI, Garmin, HERE, MapmyIndia, INCREMENT, OpenStreetMap, GIS Community, 2018. Basemap. Thompson, F., 1994. Illustrations from : An Interpretive Manual for Reports on Granular Deposits in the Inuvialuit Settlement Region: Part of the Inuvialuit Final Agreement Implementation Program, Task 7 - Sand and Gravel, Northern Affairs Program. Land Management. Indian and Northern Affairs Canada, Ottawa, Canada.

Wessel, P., Smith, W.H.F., 1996. Shorelines: Wessel, Pål, and Walter H. F. Smith. "A Global, SelfConsistent, Hierarchical, High-Resolution Shoreline Database." Journal of Geophysical Research: Solid Earth 101, no. B4 (1996): 8741-8743. https://doi.org/10.1029/96JB00104. Journal of Geophysical Research: Solid Earth 101, 8741-8743. https://doi.org/10.1029/96JB00104 